\title{
Numerical simulation of multi-hit impact on Ceramic/Composite armor
}

\author{
Nicolas Jacquet ${ }^{1 *}$, and Pascal Forquin ${ }^{1}$ \\ ${ }^{1}$ Université Grenoble Alpes, CNRS, G-INP, Laboratoire 3SR UMR5521, F-38000 Grenoble, France
}

\begin{abstract}
The numerical simulation of ballistic multi-hit impact on ceramic/composite armors is very challenging. The damage introduced by the previous hit affects the performance of the armor. In composite backings the damage is often more diffused than for metallic backings. Moreover, different sources of damage can intervene within the composite material. The present work proposes a mesoscopic scale approach to assess these issues. The $2 \mathrm{D}$ woven material is modelled with beams elements embedded in volume elements. Each component has its own material constitutive law and its damaging law. This approach allows to better model the damaging of the material, but also to better identify the material parameters from a set of basic experiments.
\end{abstract}

\section{Introduction}

Multi-hit impact response of armors is a challenging topic in mechanics. Armors are made of several components of different materials. An armor can be made of ceramic tiles and a backing. They are assembled on layers as composite materials. Glue is also used to assemble all together the armor components.

Each layer has an important role. Ceramics tiles are used to fragment or erode the core of the projectile, while the backing absorbs the kinetic energy of the projectile, and stop the remaining fragments of the projectile core. This can be viewed as the principal role of each material.

The damage process induced in ceramic tiles under impact loading has been studied in many articles (cf. [1]-[4]). The mechanical behavior of ceramics can be relatively well modelled through various constitutive models (cf. [5]-[7]). Good correlation between numerical simulations and experimental results were observed using the Denoual-Forquin-Hild fragmentation model (cf. [6]) based on spalling tests and edge-on impact tests, while the Johnson-Holmquist 2 model demonstrated good correlation with experiments when the ceramic experiences confined compression.

On the other hand, the behavior of the backing material can be more difficult to model. The modelling of the backing can be very classical for metallic material, using elasto-plastic or

* Corresponding author: nicolas.jacquet@3sr-grenobles.fr 
elasto-visco-plastic material coupled with a damage model as the unified Jonhson-Cook model (cf. [8]). When it comes to composite material backing, the modelling is more complex. Many constitutive and damaging laws exist for laminate composites (cf. [9]-[12]). The criteria developed in these models can be adapted to $2 \mathrm{D}$ woven materials such as in [13].

The other difficulties in the modelling of backing materials is to manage to capture the natural anisotropic behavior of 2D woven composites. It is also difficult to integrate in the model every sources of damage without increasing outrageously the computation time. Several technics can be used, either using a complex macroscopic constitutive law or using a mesoscopic approach as in [14] or [15].

This last approach allows to describe well each micromechanical mechanism (as the fiber failure, the matrix failure or the elasto-plastic behavior of the matrix material). These different mechanisms can be modelled through isotropic elasto-plastic laws and isotropic and multi-criteria damaging laws. In the present work, the mesoscopic modelling approach is chosen. It mixes homogenous modelling techniques with structural modelling methods, as the composite material is divided into homogenous substructures (i.e. the fibers and the matrix material). This choice is motivated in order to optimize the computation time without reducing the level of details of the model. Local damage model can be applied to the fibers or to the matrix independently. This approach allows a great flexibility in the modelling of the material behavior.

This work presents the methodology defined to model a 2D woven composite backing. The final objective is to numerically simulate a ballistic multi-hit impact on an armor structure. In a first section, the difference in terms of damaging behavior between metallic and composite materials will be presented as well as the resulting implications in a case of multihit impact. This point is particularly important to justify the mesoscopic approach selected.

Then the modelling approach to describe the composite material is presented. It is followed by two numerical examples.

\section{Damaging in the baking}

During a multi-hit impact, the damaging of each (ceramic and backing) layer can affect the performance of the armor. Indeed, if the damage develops beyond the location of the next impact, the projectile could not be contained by the backing, and perforation can occur. 


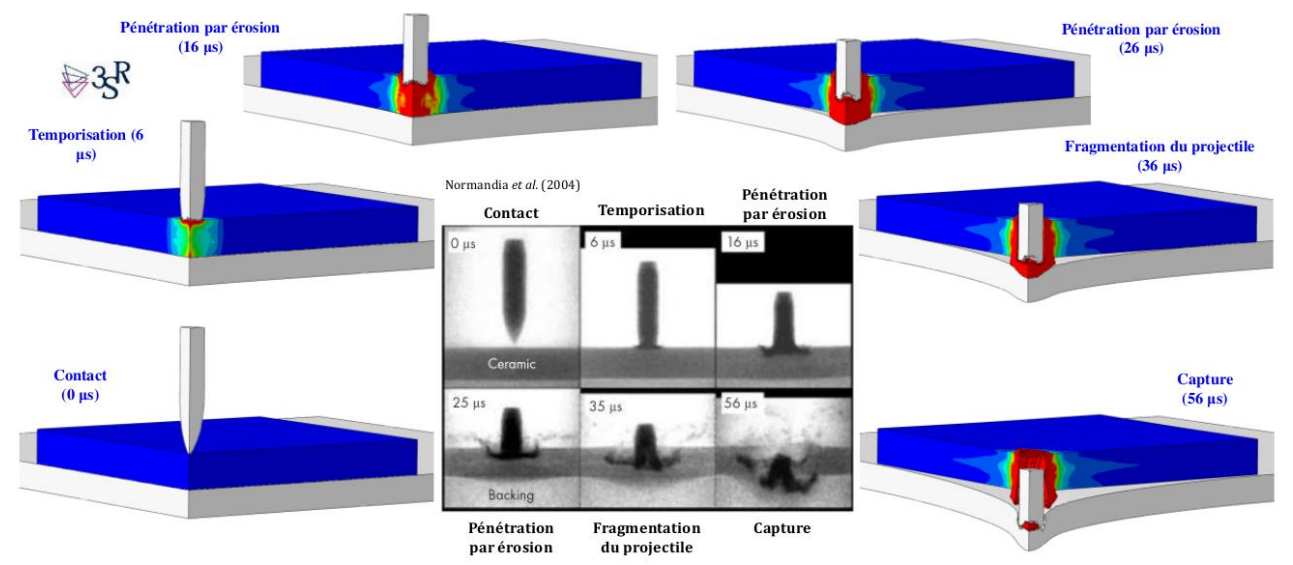

Figure 1: Evolution of the damage in the impact area during a ballistic impact [15].

The damaging of the backing material obviously depends on the constitutive material but also on the backing geometry and the applied boundary conditions.

In case of metallic backings, the damage of the material and the plastic strain are mostly located around the impact area, as it can be observed in Figure 1 from [16].

In case of composite materials, different sources of damage can be observed resulting from an impact. First the fibers and the matrix of the composite can be damaged locally in the impact area. The fibers can break under compressive, tensile or shear loading, as shown in Figure 2 from [13]. According to the thickness of the backing, the projectile can then perforate the backing.
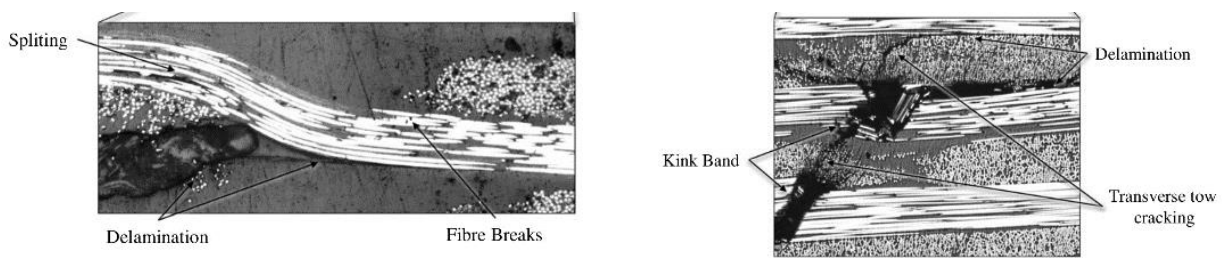

Figure 2 : Damage sources in 2D woven composite [13].

A more diffuse damage of the composite material can also be observed. The different plies of the composite backing can delaminate as shown in Figure 2 and Figure 3. The delamination can propagate far around the impact area. Because of the delamination, the stiffness of the backing is highly reduced. The performance of the backing is then degraded for the subsequent impact. Therefore, the subsequent projectile could finally perforate the backing.

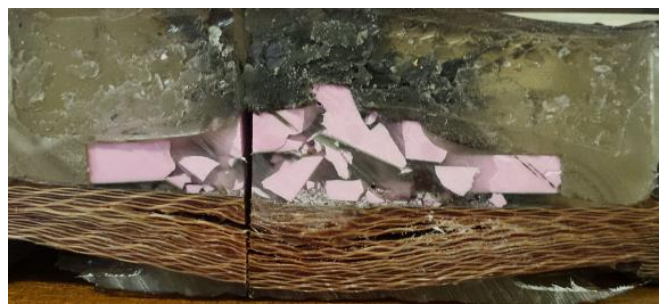

Figure 3 : Illustration of delamination in a 2D woven composite backing [17]. 
As the understanding of the damage mechanisms is difficult in a $2 \mathrm{D}$ woven composite, a mesoscopic modelling of the backing is required. It will allow to distinguish any source of damage and their evolution according to the loading. This approach will allow a better identification of the constitutive model parameters.

In the next section, the main concepts of this approach are presented.

\section{Modelling of a 2D woven backing}

The modeling of the backing can therefore be very useful in order to correctly size an armor. It can also help to understand the different induced damage mechanisms in the composite material.

In this work, we are interested in 2D woven material. It means that the backing is an assembly of several fiber plies bonded together thanks to the matrix resin. This is to be compared to $3 \mathrm{D}$ woven composite where an additional fiber is used to bond together all the plies.

A mesoscopic modelling technique is adopted in this work. It consists in describing the behavior of every components within the composite material. In this section, the details of the model are presented. First, geometrical modeling of the material is presented, then the material constitutive law is introduced.

All the modelling work presented in the article was done through Abaqus/standard and Abaqus/explicit softwares.

\subsection{Geometrical modelling}

A composite material is composed of two main components, the fibers and the matrix. In this work, the fibers are modelled through linear beams (B31) with rectangular sections as shown in Figure 4. The matrix is modelled with 3D linear volume elements (C3D8R).

The fibers are embedded in the matrix, it means that the displacement degrees of freedom of the beam are related to the ones from the $3 \mathrm{D}$ volume elements thank to the following equation:

$$
\boldsymbol{U}_{B}\left(x_{i}, y_{i}, z_{i}\right)=\sum_{j=1}^{8} N_{j}\left(x_{i}, y_{i}, z_{i}\right) \boldsymbol{U}_{j}
$$

with $\boldsymbol{U}_{B}$ the displacement of the beam node $i$, and $N_{j}$ the shape functions of the host 3D volume element and $\boldsymbol{U}_{j}$ the displacement at the nodes of the $3 \mathrm{D}$ volume element. In that way, both types of structure (beam and volume elements) interact with each other. 

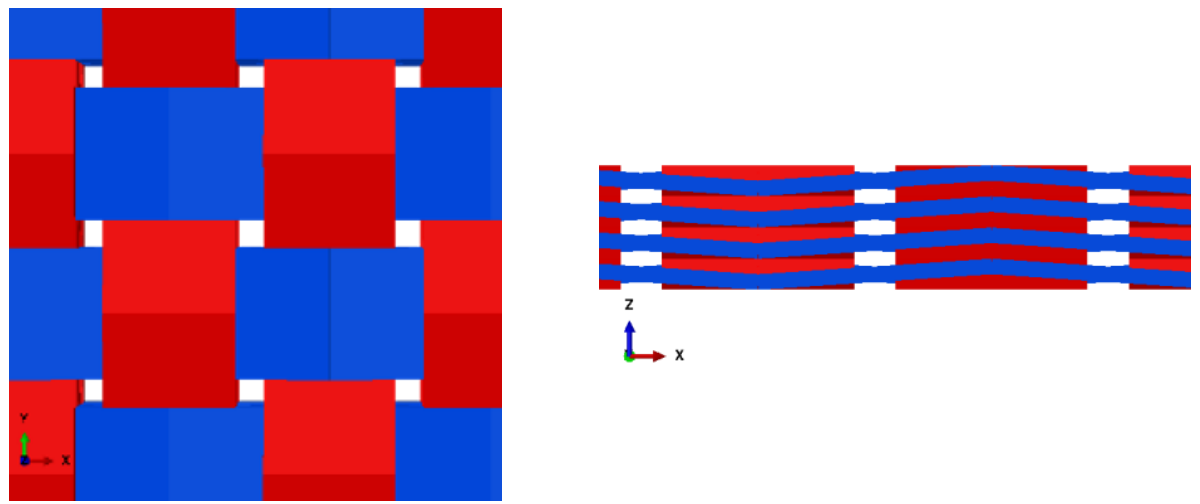

Figure 4 : Woven fibers modelled with rectangular section beams in Abaqus.

This modeling method is relatively easy to implement. It also allows assigning more simple constitutive law to each type of component (i.e. fibers and matrix). This point is detailed in the next section.

\subsection{Material modelling}

The modelling of the mechanical behavior of the backing is divided into the modelling of the healthy material behavior and its damaging.

\subsection{Constitutive law}

The material behavior of the fibers is modelled through an isotropic elastic law considering the Young's modulus $E_{f}$ and Poisson's ratio $v_{f}$ of the fiber material.

In some cases, the composite can have a nonlinear behavior in its shear orientation. The nonlinear behavior is mainly cause by the nonlinear behavior of the matrix material. In this work, the elastic behavior of the matrix is modelled with an isotropic elastic law. It is coupled with an isotropic hardening law to model the plastic behavior of the matrix. The elasto-plastic behavior of the matrix is defined by Young's modulus $E_{m}$, Poisson's ratio $v_{m}$ and the hardening law defined as follows:

$$
\mathrm{R}_{\mathrm{m}}=\mathrm{R}_{0}+\mathrm{H}_{1}\left(1-\mathrm{e}^{\left(-\mathrm{b}_{1} \cdot \mathrm{p}\right)}\right)+\mathrm{H}_{2} \cdot \mathrm{p}
$$

with $R_{0}$ the yield strength, $H_{1}$ and $b_{1}$ the parameters of the Voce hardening laws and $H_{2}$ the parameter of the linear hardening law. With this type of constitutive law, classical anisotropic and nonlinear shear behavior of 2D woven composite can be observed. This point is presented in Section 4.1.

\subsubsection{Damage laws}

The constitutive law allows to model the behavior of the composite prior fracture. As already said, different sources of damage exist within the composite material. Three different sources of damage were defined:

i. Fiber damage under tensile load: the criteria defined in [18] can be used in this case

ii. Fiber damage under compressive load: kinking of the fibers can append. Several criteria exist; the one developed for laminate composite in [18] is used here.

iii. Matrix damage: for this case, an isotropic classical damage model such as Lemaitre's damage model (cf. [19]) is used. 
iv. Finally, the delamination of the fiber is modelled through cohesive element in Abaqus following the damage criterion defined in [12].

In addition, strain-based damage evolution laws are used to define the failure of the different materials.

For fiber damage the following coupling is adopted:

$$
D=\left\{\begin{array}{l}
D_{t} \text { if: } \sigma_{1} \geq 0 \\
D_{c} \text { if: } \sigma_{1}<0
\end{array}\right.
$$

with $\mathrm{D}_{\mathrm{t}}$ the damage due to tensile loadings and $D_{c}$ the damage due to compressive loadings. It means that the damage in tension is considered when tensile loading is experienced by the fiber and the damage in compression is considered otherwise.

\section{Numerical examples}

The implementation of this model is presented in this section for some simple test cases. The list of the main material parameters used in the numerical simulation is given in .

Table 1.

Table 1 : Material parameters used for the numerical examples (cf [20], [21]).

\begin{tabular}{|l|l|c|l|}
\hline \multicolumn{2}{|c|}{ Fiber parameters } & \multicolumn{2}{c|}{ Matrix parameters } \\
\hline$E$ & $100 \mathrm{GPa}$ & $v$ & $3 \mathrm{GPa}$ \\
\hline $\mathrm{N}$ & 0.35 & $R_{0}$ & 0.3 \\
\hline$\sigma_{1}^{f}$ & $3000 \mathrm{MPa}$ & $H_{1}$ & $30 \mathrm{MPa}$ \\
\hline $\mathrm{P}$ & $1400 \mathrm{~kg} \cdot \mathrm{m}^{-3}$ & $b$ & 100 \\
\hline \multirow{2}{*}{} & & $H_{2}$ & $0 \mathrm{MPa}$ \\
\cline { 2 - 4 } & $\varepsilon_{f}$ & $0.05 \mathrm{~mm} \cdot \mathrm{mm}^{-1}$ \\
\cline { 3 - 4 } & & $\rho$ & $1150 \mathrm{~kg} \cdot \mathrm{m}^{-3}$ \\
\cline { 3 - 4 } & &
\end{tabular}

\subsection{Tensile loading at $90^{\circ}$ and $45^{\circ}$}

This first test case presents the natural anisotropic behavior of the material. A plate specimen of $10 \times 100 \times 4 \mathrm{~mm}^{3}$ is modelled and subjected to a tensile loading. Two different fiber orientations relative to the direction of loading are tested numerically, $90^{\circ}$ and $45^{\circ}$. The results are presented in Figure 5. 


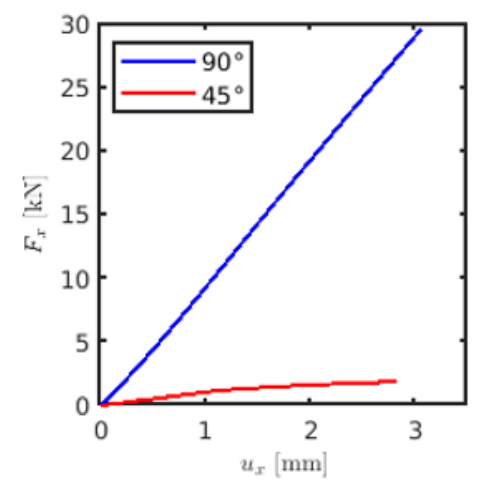

Figure 5 : Load vs. displacement for the two specimens with different orientations $\left(90^{\circ}\right.$ and $\left.45^{\circ}\right)$

One can see that the load is lower and nonlinear with the $45^{\circ}$ orientation, while with the $90^{\circ}$ orientation the load increases linearly with the displacement. It shows that, the geometric modelling coupled with the simple constitutive laws adopted for each kind of component, naturally demonstrates the anisotropic behavior generally associated to $2 \mathrm{D}$ woven composites.

\subsection{Dynamic biaxial bending of a square plate (pseudo impact test)}

This second test case presents the dynamic response of a $50 \times 50 \times 2 \mathrm{~mm}^{3}$ plate under biaxial bending. For this purpose, a $2 \mathrm{~ms}$ pressure pulse is applied at the center of the plate on a square surface of $12 \times 12 \mathrm{~mm}^{2}$. The amplitude of the pressure pulse is $50 \mathrm{MPa}$. In Figure 6(a), the speed at the center of the back face is plotted according to the time. In addition, the speed in the back face is plotted with respect to the displacement at the same location in Figure 6(b).

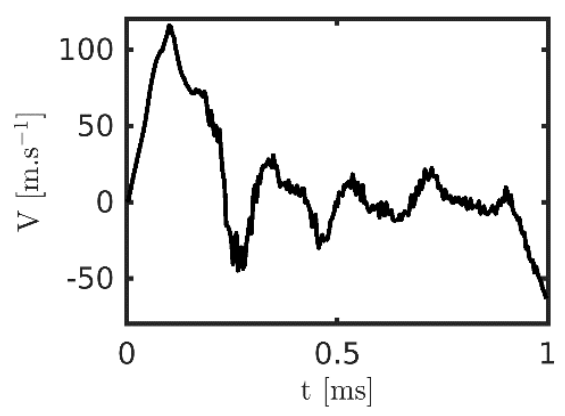

(a)

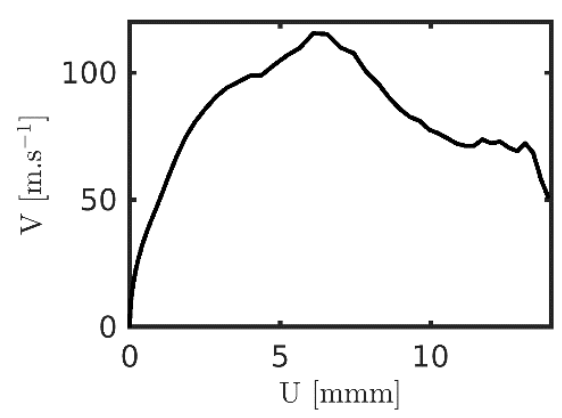

(b)

Figure $6:$ (a) Speed in the back face of the plate $\left(\mathrm{m} \cdot \mathrm{s}^{-1}\right)$ vs. Time (ms); (b) Speed in the back face of the plate $\left(\mathrm{m} \cdot \mathrm{s}^{-1}\right)$ vs. displacement $(\mathrm{mm})$.

One can see that the speed starts increasing rapidly, until a sudden decrease. This is even more visible in Figure 6(b). It corresponds to the buckling of the plate, as shown in Figure 7. 


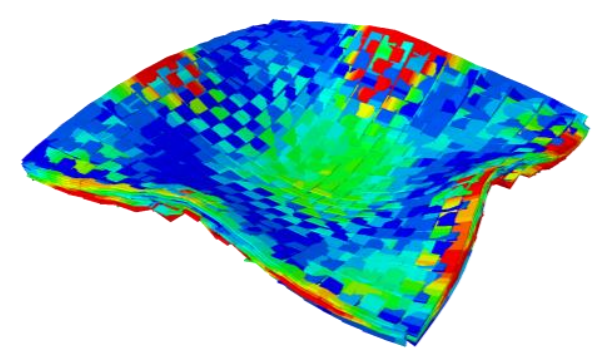

(a)

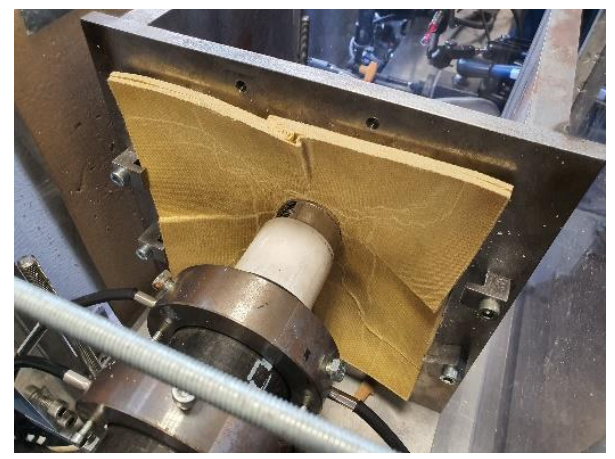

(b)

Figure 7 : Illustration of plate buckling (a) finite element model (b) experiment in 3SR

This last example shows that the developed model well seems to well describe the global behaviour of the composite material, and especially its unstable behaviour.

\section{Conclusion}

This work presents an alternative approach to model the behavior of 2D woven composite for armor. This modelling approach allows to better represents each damaging mode. This point is particularly important in the simulation of a ballistic multi-hit impact on an armor. The key properties of the developed model were presented in this article. In the near future, the parameters of the constitutive model and damaging laws will be identified through quasistatic and dynamic tensile, compressive and bending tests. The model will also be evaluated against ball multi-hit impact tests. Finally, this model should be implemented in a more complex finite element model in order to be able to accurately model a ballistic multi-hit impact on a ceramic/2D woven composite armor.

Acknowledgements: This work has been developed in the framework of the Probalics RAPID project financed by AID (Agence de l'innovation de défence, French agency of the innovation for the defense industry). This support is gratefully acknowledged.

\section{References}

[1] J. L. Zinszner, P. Forquin, et G. Rossiquet, « Experimental and numerical analysis of the dynamic fragmentation in a $\mathrm{SiC}$ ceramic under impact », Int. J. Impact Eng., vol. 76, p. 9-19, févr. 2015.

[2] J. L. Zinszner, B. Erzar, P. Forquin, et E. Buzaud, « Dynamic fragmentation of an alumina ceramic subjected to shockless spalling: An experimental and numerical study », J. Mech. Phys. Solids, vol. 85, p. 112-127, déc. 2015.

[3] D. Zhang, L. G. Zhao, et A. Roy, « Mechanical Behavior of Silicon Carbide Under Static and Dynamic Compression », J. Eng. Mater. Technol., vol. 141, n 011007, juill. 2018.

[4] N. Bourne, J. Millett, Z. Rosenberg, et N. Murray, « On the shock induced failure of brittle solids », J. Mech. Phys. Solids, vol. 46, n 10, p. 1887-1908, oct. 1998.

[5] G. R. Johnson et T. J. Holmquist, « An improved computational constitutive model for brittle materials », AIP Conf. Proc., vol. 309, nº 1, p. 981, mai 2008.

[6] P. Forquin et F. Hild, « A probabilistic damage model of the dynamic fragmentation process in brittle materials », Adv. Appl. Mech., vol. 44, p. 1, 2010. 
[7] F. Hild, C. Denoual, P. Forquin, et X. Brajer, « On the probabilistic-deterministic transition involved in a fragmentation process of brittle materials », Comput. Struct., vol. 81, no 12 , p. 1241-1253, mai 2003.

[8] G. R. Johnson et W. H. Cook, « Fracture characteristics of three metals subjected to various strains, strain rates, temperatures and pressures », Eng. Fract. Mech., vol. 21, $\mathrm{n}^{\mathrm{o}} 1$, p. 31-48, janv. 1985.

[9] A. Matzenmiller, J. Lubliner, et R. L. Taylor, « A constitutive model for anisotropic damage in fiber-composites », Mech. Mater., vol. 20, n 2, p. 125-152, avr. 1995.

[10] A. Puck et H. Schürmann, « Failure analysis of FRP laminates by means of physically based phenomenological models », Compos. Sci. Technol., vol. 62, nº 12, p. 1633-1662, sept. 2002.

[11] J. Reinoso, G. Catalanotti, A. Blázquez, P. Areias, P. P. Camanho, et F. París, « A consistent anisotropic damage model for laminated fiber-reinforced composites using the 3D-version of the Puck failure criterion ", Int. J. Solids Struct., vol. 126-127, p. 37-53, nov. 2017.

[12] J. Wiegand, " Constitutive modelling of composite materials under impact loading », http://purl.org/dc/dcmitype/Text, Oxford University, UK, 2009.

[13] N. V. De Carvalho, S. T. Pinho, et P. Robinson, « An experimental study of failure initiation and propagation in 2D woven composites under compression », Compos. Sci. Technol., vol. 71, $\mathrm{n}^{\mathrm{0}}$ 10, p. 1316-1325, juill. 2011.

[14] F. Pascal, O. Dorival, P. Navarro, S. Marguet, et J.-F. Ferrero, « Impact damage prediction in thin woven composite laminates - Part I: Modeling strategy and validation », Compos. Struct., vol. 190, p. 32-42, avr. 2018.

[15] N. V. De Carvalho, S. T. Pinho, et P. Robinson, « Analytical modelling of the compressive and tensile response of woven composites », Compos. Struct., vol. 94, n ${ }^{\circ}$ 9, p. 2724-2735, sept. 2012.

[16] Y. Duplan, « Caractérisation expérimentale et modélisation des propriétés de rupture et de fragmentation dynamiques d'un noyau de munition et de céramiques à blindage », phdthesis, Université Grenoble Alpes [2020-....], 2020.

[17] A. Healey, J. Cotton, S. Maclachlan, P. Smith, et J. Yeomans, « Understanding the ballistic event: methodology and initial observations », J. Mater. Sci., vol. 52, no 6, p. 3074-3085, mars 2017.

[18] S. T. Pinho, L. Iannucci, et P. Robinson, « Physically-based failure models and criteria for laminated fibre-reinforced composites with emphasis on fibre kinking: Part I: Development », Compos. Part Appl. Sci. Manuf., vol. 37, nº 1, p. 63-73, janv. 2006.

[19] J. Lemaitre, « How to use damage mechanics », Nucl. Eng. Des., vol. 80, n 2, p. 233-245, juill. 1984.

[20] P. A. Tarantili et A. G. Andreopoulos, « Mechanical properties of epoxies reinforced with chloride-treated aramid fibers », J. Appl. Polym. Sci., vol. 65, n 2, p. 267-276, 1997.

[21] J. Petrovic, D. Bekric, I. Vujicic, I. Dimic, et S. Putic, « Microstructural characterization of glass-epoxy composites subjected to tensile testing », Acta Period. Technol., no 44, p. 151-162, 2013. 